\title{
Substance use in adults of Yazd Greater Area, 2014- 2015: A population based study
}

\section{Behnam Bagheri}

Shahid Sadoughi University of Medical Sciences and Health Services

Mohsen Mirzaei

Shahid Sadoughi University of Medical Sciences and Health Services

Masoud Mirzaei ( $\nabla$ masoudmirzaei@yahoo.com)

Shahid Sadoughi University of Medical Sciences https://orcid.org/0000-0001-6455-0747

Research article

Keywords: Epidemiology, substance use, Yazd, Iran

Posted Date: June 2nd, 2020

DOl: https://doi.org/10.21203/rs.3.rs-31435/v1

License: (1) This work is licensed under a Creative Commons Attribution 4.0 International License.

Read Full License 


\section{Abstract}

Background: Substance use disorders (SUDs), including substance dependence or abuse, have a tremendous impact on individuals, families, communities, and governments.

Objective: The purpose of this study was to investigate the prevalence of SUDs in Yazd Greater Area during 2014-2015.

Method: This study uses data from the Yazd Health Study (YaHS) recruitment phase which was conducted from 2014 to 2015, to investigate the epidemiology of SUDs among 20-70 year-old adults. We studied 9965 participants 20-70 years old who lived in Yazd Greater Area. Data were collected using a validated questionnaire.

Results: The age-adjusted prevalence of illicit substance use was $6.2 \%$ (95\% Cl: $5 \%-7.4 \%)$. for men and $2.5 \%$ (95\% Cl: $1.7 \%-3.6 \%)$ for women. The substance use was significantly correlated with age $(r=-0.29$, $p=0.006)$, educational level $(r=-0.24, p=0.021)$, tobacco smoking $(r=0.23, p=0.001)$, and sex $(r=-0.98$, $p=0.001)$, But with hookah smoking had no significant relationship $(r=-0.01, p=0.891) .35 .6 \%$ of those consuming drugs had a previous history of addiction treatment. Also, the prevalence of substance use was greater in elders.

\section{Conclusion:}

This study indicated that the prevalence of substance use in adults of Yazd Greater Area which was correlated to the factors including consumption of cigarettes, age, and sex. The prevalence of various addictions is slightly higher than the rest of Iran.

\section{Background}

Addiction is one of the major health challenges globally, especially in Iran due to close distance to some of the major producers of illicit drugs in the world. The burden of substance use grows globally (1). The pattern of substance use varies in different parts of the world. The most common substance in Central and South America is cannabis, in Europe, they are cannabis, heroin and amphetamines; and in Asia opium and hashish are the most commonly used substances by the addicts(2).

Opium usage for medicinal or recreational purposes has a long history in various parts of the world (3). It has been reported that more than 20 million people use opium in different forms such as inhalation or oral consumption (4). Addiction has been permeated the whole world, mainly Iran which is located in the neighborhood of the main drug production country (Afghanistan), and is in the transit corridor of drug transport to Europe (5).

Due to stigma and legal prohibition on substance use, research on prevalence and patterns of illicit substance use is difficult and requires special considerations. Furthermore, epidemiological research on these disorders requires the use of valid instruments, highly trained and qualified interviewers, lengthy 
interviews and rigorous quality control of the study procedures. Thus, there is a paucity of accurate data on illicit substance use and dependence in many countries in comparison to the data on smoking and alcohol usage (6).

According to World Health Organization (WHO) statistics in 2012, around 5.2\% of the world's population aged 15-64 have at least one experience of illegal substance abuse in the previous year, mainly Marijuana, opiates, cocaine, or amphetamine-type stimulant(7). Opium addiction and its derivatives in Asian countries has been indicated to be about 6 percent(8).

According to a meta-analysis (In 2015), of 58 studies in Iran, the prevalence of opium use was 22\% (95\% Cl: 21.3\%-22.7\%)(9). In Kerman province, the neighboring province of Yazd, the prevalence of substance abuse in 2010 is reported to be $225 \%$ (10).

According to the large population-based studies, there is poor evidence about the prevalence of drug addiction in Iran. Therefore, this study aims to investigate the epidemiology of substance use in a large representative population of Yazd including 10,000 people aged 20-69 years old in Yazd city located in center of Iran.

\section{Methods And Materials:}

\section{Study population}

This cross-sectional analytic study was conducted on data from recruitment phase of the Yazd Health Study (YaHS) in 2014-2015. YaHS is a population-based prospective cohort study conducted on 10,000 residents aged between 20-70 years old in Yazd greater area. The sampling method was populationbased, random and multi-stage. 10,000 residents of YGA aged 20 to 69 years were selected using cluster random sampling method. 200 clusters were randomly selected based on participants' residential postcode. Then, each cluster of 50 samples was divided into the following subgroups: 25 men and 25 women; five people in each sex in each ten-year age range categories (20-29, 30-39, 40-49, 50-59 and 6069 years old). Trained interviewers completed a validated questionnaire (Cronbach's alpha was $0.89 \%$, and therefore the questionnaire was considered reliable).A detail of the methodology of YaHS was published elsewhere. (11)

\section{Ethical consideration:}

All participants were informed about the study objectives and signed the written consent form at the beginning of the study. In this study, the variables related to the demographic questionnaire and the substance use status inventory questionnaire were used to examine the status of addiction in each person. 
The procedure of this study was approved by the Ethics Committee of School of Public Health, Shahid Sadoughi of Medical Sciences, Yazd, Iran; number IR.SSU.SPH.REC.1396.136

\section{Statistical analysis}

The Statistical Package for Social Sciences (SPSS) software version 21 (SPSS, Inc. Chicago, IL, USA) was used for statistical analysis. Descriptive statistics were reported as frequency and percentage. The Pearson correlations with " $r$ " and chi-square analysis with a significant level of 0.05 were used.

\section{Results}

Out of 9965 participants in the YaHS study, 4864 were men and 4942 were women. The baseline characteristics of the participants were presented in Table 1.

Table 1

Baseline characteristics of Yazd health Study (Phase 1) 2014-2015

\begin{tabular}{|llll|}
\hline Variable & Variable subgroup & Frequency & Percent \\
\hline \multirow{2}{*}{ Sex } & Male & 4864 & 49.6 \\
\cline { 2 - 4 } & Female & 4942 & 50.4 \\
& Married & 8345 & 85.1 \\
\cline { 2 - 4 } & Single & 1029 & 10.5 \\
\cline { 2 - 4 } Education & Widow & 374 & 3.8 \\
\cline { 2 - 4 } & divorced & 55 & 0.6 \\
\cline { 2 - 4 } & Primary school and less & 2550 & 26.1 \\
\cline { 2 - 4 } & High school & 2772 & 28.4 \\
\cline { 2 - 4 } & Diploma and graduate diploma & 2908 & 29.8 \\
\cline { 2 - 4 } & BSc & 1275 & 13.1 \\
\cline { 2 - 4 } & MSc and Doctorate & 249 & 2.6 \\
\cline { 2 - 4 } & Yes & 7522 & 77.2 \\
\cline { 2 - 4 } & No & 2226 & 22.8 \\
\cline { 2 - 4 } & &
\end{tabular}

The age-adjusted prevalence of illicit substance use was $6.2 \%$ (95\% Cl 5\%-7.4\%) for men and 2.5\% (95\% $\mathrm{Cl} 1.7 \%-3.6 \%$ ) for women. Overall, $95.3 \%$ of participants have never used drugs. $35.6 \%$ of those consuming drugs had a previous history of addiction treatment (Table 2). There was a significant relationship between age, sex, and illicit drug usage. The prevalence of substance consumption in men 
was almost three times more than women (Table 3). In general, substance use was significantly higher in males compared to women ( $\mathrm{p}$-value $<0.05$ ). Also, the prevalence of substance use was greater in elders. In addition, substance use was more prevalent at lower education status ( $p$-value $<0.05$ ).

Table 2

Prevalence of substances consumption of Yazd health Study (Phase 1) 2014-2015

\begin{tabular}{|llll|}
\hline Type of addiction & Type of use & Frequency & percent \\
\hline Illicit drugs & Yes & 133 & 1.4 \\
\cline { 2 - 4 } & Sometimes & 312 & 3.3 \\
\cline { 2 - 4 } & No & 9072 & 95.3 \\
\cline { 2 - 4 } & Total & 9517 & 100 \\
\hline
\end{tabular}

Table 3

The relationship between age, gender and substance use of Yazd health Study (Phase 1) 2014-2015

\begin{tabular}{|c|c|c|c|c|c|c|c|}
\hline \multirow[t]{2}{*}{ Variable } & \multirow[t]{2}{*}{ Subgroup } & \multirow[t]{2}{*}{ Drugs } & \multicolumn{4}{|c|}{ Type of use } & \multirow{2}{*}{$\begin{array}{l}\mathrm{p} \text { - } \\
\text { value }\end{array}$} \\
\hline & & & Yes & $\begin{array}{l}\text { Some } \\
\text { times }\end{array}$ & Quitted & No & \\
\hline \multirow[t]{5}{*}{ Age } & $20-29$ & \multirow[t]{5}{*}{ Drugs } & 11 & 58 & - & 1791 & \multirow[t]{5}{*}{0.001} \\
\hline & $30-39$ & & 22 & 69 & - & 1849 & \\
\hline & $40-49$ & & 20 & 59 & - & 1873 & \\
\hline & $50-59$ & & 48 & 75 & - & 1779 & \\
\hline & $60-69$ & & 31 & 47 & - & 1738 & \\
\hline \multirow{2}{*}{ Sex } & Male & \multirow[t]{2}{*}{ Drugs } & 116 & 205 & - & 4404 & \multirow[t]{2}{*}{0.001} \\
\hline & Female & & 16 & 106 & - & 4634 & \\
\hline \multirow{5}{*}{$\begin{array}{l}\text { Level of } \\
\text { Education }\end{array}$} & Primary school and less & \multirow[t]{5}{*}{ Drugs } & 28 & 71 & - & 2267 & \multirow[t]{5}{*}{0.002} \\
\hline & High school & & 55 & 90 & - & 2350 & \\
\hline & $\begin{array}{l}\text { Diploma and graduate } \\
\text { diploma }\end{array}$ & & 24 & 86 & - & 2520 & \\
\hline & BSc & & 9 & 28 & - & 1090 & \\
\hline & MSc and Doctorate & & 1 & 4 & - & 209 & \\
\hline
\end{tabular}


Table 4 shows the correlation between tobacco smoking and substance use. There was a significant relationship between substance use and smoking.

Table 4

The relationship between substance use and smoking variables of Yazd health Study (Phase 1) $2014-2015$

\begin{tabular}{|llllllll|}
\hline Variable & & \multicolumn{2}{c}{ Smoking } & & & Total & p-value \\
\cline { 2 - 7 } & & Yes & Sometimes & Quitted & No & & \\
Substance use & Yes & 85 & 3 & 5 & 37 & 130 & 0.001 \\
\cline { 2 - 7 } & Sometimes & 63 & 27 & 11 & 207 & 308 & \\
\cline { 2 - 7 } & No & 693 & 151 & 166 & 7886 & 8896 & \\
\hline
\end{tabular}

The relationship between variables such as age, gender, education level, marital status, and substance use was evaluated using logistic regression model. The results of this analysis showed that age ( $p$-value: 0.001), and sex ( $p$-value: 0.002) were significantly related to Substance use.

\section{Discussion:}

Substance use is a multi etiological universal phenomenon with notable adverse impacts on public health(12). The disorders link to substance use categorized in chronic type of diseases which is treatable in some and uncontrollable in others(13).

In this study; the prevalence of drug use was $6.22 \%$ for men and $2.64 \%$ for women. The drug consumption in 50-59 years old males was highest (??). In 2008, around 12-22 million people, half of them in Asia and the other half in America, Europe, Africa, and Oceania used opium (14). Based on an epidemiological study in 2014, approximately 20.2 million adults aged 18 or older had a past year substance use in the United States. Of these adults, 16.3 million had an alcohol use disorder and 6.2 million had an illicit substance use disorder(15). Westermeyer et al. (1981) reported that the production of opium and its trade could be severely influenced by the spread of Asian communities. Poppy producing communities tend to have the highest crude prevalence rates (over 6 addicts per 100 people).

Communities involved with opium transshipment generally have intermediate rates (3 to 6per 100 people). End-use or consuming locales have the lowest rates (under 3 per 100 people). (8) According to the United Nations Office on Drugs and Crime (UNODC) report published in 2011, the prevalence of opium use and its derivatives in Turkey was $5.0 \%$, and the prevalence of cannabis, opium and its derivatives consumption, and opiate-related chemicals was $6.5 \%$ in the Middle East and Southwest Asia (16). Recent studies suggest that Iran and Yazd are among the areas with the highest prevalence of substance use disorders(17). According to the earlier studies in Iran, there are different patterns of substance use in 
urban and rural areas. The prevalence of opium use in rural areas is higher than urban areas, and alcohol consumption and psychotropic substances are found? to be higher in urban areas(18).

The prevalence of (opium consumption in 50045 participants of the Golestan cohort study aged 40-75 years in 2011 was am, 17\% (19). The prevalence of substance use in Golestan is higher than our findings, which can be associated with this difference in ethnicity (Turkmen race), as well as different age ranges of the two studies (19).

In an epidemiological study by Fallahzadeh et al. (20), in Valashahr region and 93 of the villages in that area (Fars province in southern Iran), the prevalence of opium use among 9,000 adults in 2012 to 2014, aged $75-40$ was $8.4 \%$ (17.3\% in men and $0.7 \%$ in women); this study was derived from Persian cohort study. The most important distinction of their study with the present study is age range, geographic region difference and sampling method. In another study conducted in 2003 in Babol province in Iran, out of 310 adults aged $16-80$ years, the prevalence of opium use was $8.9 \%(n=42)(21)$ which determined that opium was the most commonly used drugs. According to a report in rural areas of Kerman province in south- east of Iran, substance use has been increased dramatically during a 12-years period (from 2000 to 2012) (22). In reports from Kerman, Golestan, Babol (Mazandaran) and Valashahr (Fars), in accordance with our study results, substance abuse, especially opium, was higher among men than women(19, 21, 22).

In 2003, Bashardost et al. (23) estimated the prevalence of substance use at $5.0 \%$ among 6400 randomly selected men in Isfahan.Yazd has a lower prevalence of substance use disorder than the northern regions of Iran $(19,20,24)$.According to the results of these studies, Iran, in the vicinity of countries producing narcotics (poppy) and in some way its passage, is in the high-risk area in terms of the prevalence of substance use, its production and transportation(8). Based on a meta-analysis study, it has been confirmed that: smoking is considered a risk factor for substance use disorders, and significantly increases the risk of substance use disorders $(25,26)$. As in the present study, this relationship between smoking and substance use disorders was significant. According to the geographical center of Yazd Greater area in the country that places this city more on the illicit drug trafficking route, the estimated prevalence in this study is somewhat predictable(17).

This study used data of a YaHS which is a large study with a population-based sample frame (9) that can be generalized to the population of Yazd province. This study was also conducted at the place of transit of drugs from neighboring countries to the rest of country and the world, which could be important.

Our findings should be interpreted while considering the main limitation. Substance use was investigated by a questionnaire and self-report in participants, which is a common limitation of most epidemiologic studies on this matter. Another issue was the stigma to report on substance use by the individual in Yazd conservative community that may have affected the results.

\section{Conclusion:}


The high prevalence of substance use among adults in Yazd Greater Area was correlated with age, and sex which raising the necessity of future well-conducted studies to reduce the risk of subsequent substance dependence and other adverse outcomes.

\section{Abbreviations}

SUDs: Substance use disorders

YaHS: Yazd Health Study

Cl: Confidence Interval

WHO: World Health Organization

YGA: Yazd greater area

SPSS: The Statistical Package for Social Sciences

UNODC: United Nations Office on Drugs and Crime

\section{Declarations}

\section{Ethics approval and consent to participate}

All participants were informed about the study objectives and signed the written consent form at the beginning of the study. In this study, the variables related to the demographic questionnaire and the substance use status inventory questionnaire were used to examine the status of addiction in each person.

The procedure of this study was approved by the Ethics Committee of School of Public Health, Shahid Sadoughi of Medical Sciences, Yazd, Iran; number IR.SSU.SPH.REC.1396.136

\section{Consent for publication}

Not applicable.

\section{Availability of data and material}

The data collected by Yazd Health Study are not open access but can be shared under conditions of collaboration and endowment. Data are available from the authors upon reasonable request and with permission of principal investigator. For further information, please visit YaHS website at www.yahs.ir / yahs.ssu.ac.ir 


\section{Competing interests}

No conflict of interest was declared.

\section{Funding}

This work was funded by Shahid Sadoughi University of Medical Sciences.

\section{Authors' contributions}

The conception of the research idea was conducted by Masoud Mirzaei (MM1) and Behnam Bagheri (BB) designed the study. Conducted the study under the supervision of MM1. BB analyzed the data and wrote the draught of the manuscript. Mohsen Mirzaei (MM2) reviewed and critically revised the manuscript. All authors read and approved the final manuscript. MM1 finalized the manuscript.

\section{Acknowledgements}

This article is the result of YaHS research project, supported by the Deputy for Research at Shahid Sadoughi University of Medical Sciences and Iran $\mathrm{MOH}$. Thanks to people of Yazd for making YaHS possible.

\section{References:}

1. Ahmadvand M. Addiction (etiology and treatment). Tehran, Iran: Publications of Payam Noor University. 2002.

2. Ghodse H. Addiction. A matter of substance. Health Serv J, 1995;105(5445):31.

3. Schiff PL. Opium and its alkaloids. Am. J. Pharm. Educ. 2002;66(2):186-96.

4. Merz F. United Nations Office on Drugs and Crime: World Drug Report 2017. 2017. SIRIUS-Zeitschrift für Strategische Analysen. 2018;2(1):85-6.

5. Moosavi N, Hezardastan F, Atashpoor H, Markazi F. The Comparison of Irrational Beliefs and Impulsivity Between Obsessive-Compulsive Clinical and Non-Clinical Women in Isfahan. World Applied Sciences Journal. 2012;20(1):164-9.

6. Degenhardt L, Bucello C, Calabria B, Nelson P, Roberts A, Hall W, et al. What data are available on the extent of illicit drug use and dependence globally? Results of four systematic reviews. Drug and alcohol dependence. 2011;117(2-3):85-101.

7. Crime U. World drug report. 2014. New York. 2012.

8. Westermeyer J. Opium availability and the prevalence of addiction in Asia. British journal of addiction. 1981;76(1):85-90. 
9. Ansari-Moghaddam A, Rakhshani F, Shahraki-Sanavi F, Mohammadi M, Miri-Bonjar M, Bakhshani NM. Prevalence and patterns of tobacco, alcohol, and drug use among Iranian adolescents: A metaanalysis of 58 studies. Children and Youth Services Review. 2016;60:68-79.

10. Golestan S, Abdullah HB, Ahmed N, Anjomshoa A. Environmental factors influencing relapse behavior among adolescent opiate users in Kerman (a province in Iran). Glob J Hum Soc Sci. 2010;10(4):71-6.

11. Mirzaei M, Salehi-Abargouei A, Mirzaei M, Mohsenpour MA. Cohort Profile: The Yazd Health Study (YaHS): a population-based study of adults aged $20-70$ years (study design and baseline population data). International journal of epidemiology. 2018 Jun 1;47(3):697-8h.

12. Atwoli L, Mungla PA, Ndung'u MN, Kinoti KC, Ogot EM. Prevalence of substance use among college students in Eldoret, western Kenya. BMC psychiatry. 2011;11(1):34.

13. Miller WR, Forcehimes AA, Zweben A. Treating addiction: A guide for professionals: Guilford Press; 2011.

14. Metcalfe C, Tindale K, Li H, Rodayan A, Yargeau V. Illicit drugs in Canadian municipal wastewater and estimates of community drug use. Environmental pollution. 2010;158(10):3179-85.

15. Lipari RN, Van Horn SL. Trends in substance use disorders among adults aged 18 or older. The CBHSQ Report: 2017 Jun 29.Substance Abuse and Mental Health Services Administration (US); 2017.

16. Sandeep C. World drug report 2011. United Nations Publication: United Nations Office On Drugs and Crime (UNODC). 2011.

17. Drugs UNOo, Crime. World drug report 2010: United Nations Publications; 2010.

18. Ziaaddini H, Sharifi A, Nakhaee N, Ziaaddini A. The prevalence of at least one-time substance abuse among Kerman pre-university male students. Addiction \& health. 2010;2(3-4):103.

19. Khademi H, Malekzadeh R, Pourshams A, Jafari E, Salahi R, Semnani S, et al. Opium use and mortality in Golestan Cohort Study: a prospective cohort study of 50000 adults in Iran. BMJ. 2012;344:e2502.

20. Fallahzadeh MA, Salehi A, Naghshvarian M, Fallahzadeh MH, Poustchi H, Sepanlou SG, et al. Epidemiologic Study of Opium Use in Pars Cohort Study: A Study of 9000 Adults in a Rural Southern Area of Iran. Archives of Iranian Medicine (AIM). 2017;20(4).

21. Meysamie A, Sedaghat M, Mahmoodi M, Ghodsi S, Eftekhar B. Opium use in a rural area of the Islamic Republic of Iran. 2009.

22. Ziaaddini H, Ziaaddini T, Nakhaee N. Pattern and trend of substance abuse in eastern rural Iran: A household survey in a rural community. Journal of addiction. 2013;2013.

23. Bashardoost N, Tirani M. Prevalence of addiction in males: Isfahan 2003. ARYA Atherosclerosis. 2010;1(2).

24. Ahmadi J, Pridmore S, Alimi A, Cheraghi A, Arad A, Parsaeyan H, et al. Epidemiology of opium use in the general population. The American journal of drug and alcohol abuse. 2007;33(3):483-91. 
25. Rajabi A, Dehghani M, Shojaei A, Farjam M, Motevalian SA. Association between tobacco smoking and opioid use: a meta-analysis. Addictive behaviors. 2019;92:225-35.

26. Degenhardt L, Dierker L, Chiu WT, Medina-Mora ME, Neumark Y, Sampson N, et al. Evaluating the drug use "gateway" theory using cross-national data: consistency and associations of the order of initiation of drug use among participants in the WHO World Mental Health Surveys. Drug and alcohol dependence. 2010;108(1-2):84-97. 